\title{
Las letras como entradas del diccionario
}

\author{
José-Álvaro Porto Dapena \\ Universidade de A Coruña
}

Si partimos de la idea, aceptada por la generalidad de los diccionarios, de que éstos no son otra cosa que recopilaciones de palabras pertenecientes a una determinada lengua sobre las cuales se ofrece alguna información ${ }^{1}$, parece obvio postular que las entradas que constituyen su macroestructura no podrán estar integradas más que por palabras ${ }^{2}$. Y en principio esto es lo que ocurre de hecho: la lexicografía de las lenguas occidentales -incluida por tanto la española- respeta en términos generales esta norma, pues en definitiva de lo que se trata es de estudiar el léxico de una lengua. Y digo en principio porque, luego, una cosa es predicar y otra dar trigo: en la práctica el diccionario da a veces la impresión de ser un híbrido, una mezcla variopinta de cosas donde no siempre las palabras son precisamente las protagonistas, confundiéndose con frecuencia éstas con las realidades que representan e incluso alguna vez introduciendo como entradas elementos que no solo no son palabras, sino que ni siquiera pertenecen a ningún tipo de unidades lingüísticas. Y esto es precisamente lo que ocurre con las letras, cuyo registro en los diccionarios generales es unánime, aun cuando su conside-

1 Para una discusión acerca del significado de la palabra diccionario, véase Alvar Ezquerra (1980: 103-119) o Alvar Ezquerra (1993: 59-72).

2 No voy a entrar aquí en la discusión acerca de la problemática en torno a la existencia de la palabra, problemática que, al decir de J. M. González Calvo (1998a: 11 y ss., y 1998b: 243 y ss.), no es superior a la planteada por la existencia del morfema o de la oración, así como tampoco me voy a referir a la cuestión de si la macroestructura del diccionario debe estar constituida por vocablos, lexemas u otro tipo de unidades lingüísticas. Para esta última cuestión me remito, por ejemplo, a R. Werner (1982: 219 y ss.) y Alvar Ezquerra (1993: 89 y ss.). 
ración como entradas no siempre viene avalada por su condición de verdaderos vocablos o, por lo menos, de unidades pertenecientes al sistema léxico. Por otro lado, en su estudio dentro de los diccionarios es bastante frecuente observar una serie de confusiones que, a la luz de los conocimientos lingüísticos que hoy poseemos sobre la materia, pueden resultar chocantes y hasta incomprensibles: por lo común se hallan mezclados $-\mathrm{y}$ a veces confundidos- los niveles gráfico y fónico, y en este último caso tampoco aparecen claramente definidos entre sí los aspectos fonético y fonológico. Parece como si la lexicografía en este punto concreto hubiera quedado anclada en el pasado sin haberse apenas beneficiado de los modernos avances en materia fonética, fonológica y grafemática.

En las páginas que siguen me voy a ocupar del tratamiento de que en los principales diccionarios de nuestra lengua -atendiendo en especial a los del español actual-son objeto las letras de nuestro alfabeto. ¿Es correcto que éstas, observadas en su pura representación gráfica, figuren como entradas o componentes de la nomenclatura del diccionario? ¿Se justifica que, todavía hoy, se sigan confundiendo en los registros lexicográficos las letras con los fonemas que representan, definiendo, por ejemplo, aquéllas con los rasgos pertinentes de éstos o asignándoles, en fin, una determinada pronunciación o realización fónica? Pensamos que en lexicografía teórica se ha reflexionado poco sobre este punto, lo que -podría pensarse- habrá llevado a que los diccionarios actuales, empujados por la inercia de una multisecular tradición, sigan presentando en este como en otros aspectos la pátina acumulada por el paso de los años.

\section{LETRAS GRÁFICAS Y LETRAS LÉXICAS}

Aunque ya en el Vocabulario de romance en latín de Nebrija (1495) se incluyen dos letras, la A y la V como entradas, es -pienso- a partir del Tesoro de la lengua castellana o española de S. de Covarrubias (1611) cuando se introduce en la lexicografía española la costumbre de tratar los componentes del alfabeto, al lado de las palabras y elementos léxicos en general, como cabeceras de artículos independientes, produ- 
ciéndose la consagración definitiva de este procedimiento en el Diccionario de autoridades (1726-1737), que en este como en otros puntos sigue de cerca los pasos de Covarrubias ${ }^{3}$. La decisión de incluir las letras entre las entradas del diccionario parece justificarse por el hecho de que se trata de elementos pertenecientes a la lengua escrita, precisamente aquella en la que se halla realizado el propio diccionario, y al mismo tiempo porque representan el inicio o rúbrica de cada uno de los capítulos o partes en que se estructura todo diccionario alfabético, al representar la letra inicial de todas las palabras que siguen a continuación. El problema, sin embargo, viene dado por el hecho de que las letras, tomadas en su escueta configuración gráfica, no son propiamente palabras -de ahí que, con muy buen criterio, ni Covarrubias ni Autoridades las asignen en los artículos correspondientes a ninguna categoría o subcategoría de vocablos-, sino puros objetos o realidades que, como tales, pueden -eso sí- ser designadas a su vez mediante una serie de palabras disponibles en la lengua, palabras que, curiosamente, no se hallan por cierto registradas en ninguno de estos dos diccionarios a que me acabo de referir.

Esto último no ocurre, sin embargo, en lo diccionarios modernos, en los que las letras son objeto de un doble registro: como realidades gráficas $(\mathrm{a}, \mathrm{b}, \mathrm{c}, \mathrm{d} . .$.$) y como unidades léxicas (a, b e, c e, d e$, hache, etc.). Es decir, las letras aparecen registradas, por una parte, en su forma estrictamente gráfica, que -repito- como tal forma gráfica no constituye palabra alguna, sino más bien en todo caso un puro signo representante de un fonema o sonido lingüístico, y, por otra, en sus formas propiamente léxicas, esto es, como verdaderas palabras, constituidas por sus respectivos nombres. Y, evidentemente, contra lo que pudiera pensarse, ambos registros no son ni mucho menos equivalentes, ya que corresponden a niveles semiológicos distintos: en el primer caso las letras ca-

3 Las huellas de Covarrubias a este respecto en el Diccionario de autoridades son evidentes, como cuando, en el artículo correspondiente a A, éste se hace eco de la idea, expresada en el Tesoro, de que los varones cuando nacen expresan su llanto con la A de Adán en tanto que las mujeres lo hacen con la E de Eva, "como lamentándose de sus primeros padres". 
be interpretarlas como representantes de fonemas y en el segundo como nombres o representantes de las letras mismas, de modo que tenemos, por ejemplo, cadenas como la siguiente, donde cada elemento es representado por el que se sitúa inmediatamente después de la flecha:

$$
/ \mathrm{b} / \rightarrow \mathrm{b} \rightarrow \text { be }
$$

Esto supuesto, b y be tienen naturaleza diferente y, por lo tanto, no son en absoluto sinónimas; de ahí que, como señalé en otro lugar, una expresión escrita como

Be es el nombre de $b$

tiene todo el sentido del mundo, frente a su lectura o realización fónica, que a su vez podría representarse gráficamente

Be es el nombre de be,

donde solo aparece el sustantivo be, y por lo tanto la frase podría sonar a tautológica 5 .

La pertenencia, en fin, de $\mathrm{b}$ y be a niveles semiológicos distintos viene determinada por el hecho de que ambas forman parte de paradigmas muy diferentes: mientras $b$ corresponde al paradigma que llamamos alfabeto, esto es, a la serie a, b, c, d, etc., constituyentes de un código gráfico, paralelo pero independiente del sistema fonemático, be por su lado forma parte, junto a ce, equis, hache, jota, etc., de un campo semántico o paradigma léxico, y, consiguientemente, parece que solo en este último caso las letras deberían tener cabida en el diccionario. Notemos por cierto la incoherencia de los diccionarios tradicionales en este punto al registrar las letras gráficas como entradas y no aceptar, en cambio, como tales otros elementos igualmente gráficos, concretamente las comillas ("“), signos de interrogación ( $₫$ ?) y de admiración ( $i$ !),

4 Cfr. Porto Dapena (1999: 135).

5 Aunque bien mirado no lo es, puesto que las dos apariciones de be corresponden aquí a niveles metalingüísticos distintos: con referencia a sí mismo, esto es, a la palabra be en el primer caso, y al objeto constituido por la letra en el segundo, de modo que la expresión es parafraseable por esta otra:

La palabra be es el nombre de la letra be. 
guión (-), incluyendo los propios puntos y comas. Lógicamente, la inclusión de estos últimos elementos en el diccionario no tendría sentido, porque, como las letras, no forman parte del sistema léxico ${ }^{6}$.

Cabe, a pesar de todo, aceptar una leve posibilidad de justificar la presencia de las letras gráficas en la nomenclatura del diccionario. Tal posibilidad se produciría tan solo en el caso de que con las entradas a, b, c, d, etc. no se pretendiera presentar las letras propiamente dichas, sino sus respectivos nombres, lo que en cierto modo justificaría hablar de las equivalencias

$$
\mathrm{a}=a ; \mathrm{b}=b e ; \mathrm{c}=c e, \mathrm{~h}=\text { hache, etc. }
$$

Nótese, sin embargo, que en ese caso las letras adquirirían una dimensión semiológica distinta y, en lugar de fonemas como es lo habitual, pasarían a representar verdaderas palabras; es decir, se produciría en realidad esta otra cadena de representaciones:

$$
/ \mathrm{b} / \rightarrow \mathrm{b} \rightarrow b e \rightarrow \mathrm{B}
$$

que interpretamos en el sentido de que el fonema /b/ se representa con la letra $\mathrm{b}$, a la que corresponde el nombre be $\mathrm{y}$, a su vez, éste es indicado nuevamente por $\mathrm{B}^{7}$. Evidentemente, $\mathrm{B}$ sería aquí una palabra, aunque abreviada gráficamente, lo que la convertiría en una especie de sigla o símbolo de "be".

6 A este propósito aprovecho la ocasión para señalar que por la misma razón tampoco se justifican entradas como $b \ldots b, b \ldots c h, m m m, z \ldots . . z$, registrados en el DuE de $\mathrm{M}^{\mathrm{a}}$ Moliner, pues no constituyen propiamente palabras por más de que la lexicógrafa aragonesa les atribuye un cierto significado.

7 De hecho en el lenguaje escrito la mención de las letras se hace tal vez más frecuentemente por medio de las letras mismas que con los correspondientes nombres, los cuales se usan desde luego poco. Curiosamente, los manuales de Ortografía -incluida la reciente Ortografía de la lengua española (1999) de la RAE- no se ocupan para nada del asunto. En una encuesta realizada por mí entre profesores de lengua española, mediante el dictado de frases en que aparecían mencionadas las letras, se observa una gran vacilación entre la representación gráfica y léxica, con preferencia, efectivamente, por la primera, y con la tendencia a utilizar únicamente la segunda en el uso metalingüístico (Hache se escribe con h) y en los plurales (Beber se escribe con dos bes).

8 Puesto que aquí a su vez todas estas distinciones las estamos expresando gráficamen- 
Y esta en verdad podría pensarse que es la interpretación de los diccionarios modernos, que, con el de la Academia a la cabeza, dan la impresión de que consideran como sustantivos las letras gráficas, puesto que las someten a categorización mediante la marca $f$ de femenino'; porque es evidente que, si tales signos se entendieran como puras letras, atribuirles un género sería tan absurdo como decir, por ejemplo, que una silla, además de pies, tiene dos sílabas: evidentemente, el género es tan solo atribuible a los nombres be, ce, de, efe, no a los objetos que éstos representan. Ahora bien, si el registro de las letras gráficas respondiera verdaderamente a esa interpretación, habría que señalar, consecuentemente, algunas incoherencias de los diccionarios:

a) En primer lugar, no habría razón para introducir como entradas las siglas o símbolos correspondientes a las letras be, de, hache, jota, etc. y desechar, en cambio, las correspondientes a otras palabras o expresiones -algunas utilizadas incluso dentro del propio diccionario-, como, por ejemplo, $f$ (femenino), $s$ (sustantivo), E (Este), P (padre), D (don), @ (arroba) y un larguísimo etcétera. Es más: resulta significativo el hecho de que los diccionarios de siglas y abreviaturas ${ }^{10}$ no tengan en cuenta para nada entre éstas las letras del alfabeto.

b) Si de representar formas gráficas abreviadas se trata, no se explica por qué los diccionarios no registran asimismo, por ejemplo, los guarismos 1,2,3,4, etc. junto a los signos verbales correspondientes, uno, dos, tres, cuatro, que son, sin embargo, los únicos que aparecen.

te, creo necesario acudir a las siguientes convenciones: como es habitual, el nivel fonemático se representa con una letra entre barras oblicuas, el nivel gráfico con letras minúsculas en redonda, el nivel léxico con letras en cursiva y, finalmente, el nivel de siglas o símbolos con letras mayúsculas.

9 Esta categorización en realidad no se introduce en el DRAE hasta la ed. de 1925, si bien el Diccionario manual todavía permanece sin presentar marca de femenino en la ed. de 1927.

10 Véase, por ejemplo, el de J. C. Galende (1997). 
c) Otra incoherencia la constituye sin duda el tratamiento que se da en los diccionarios a otros sistemas gráficos, como, por ejemplo, al alfabeto griego, cuyas letras aparecen registradas, pero tan solo en su representación léxica; es decir, encontramos épsilon, pero no $\varepsilon$, omega o pi, pero no $\omega$ o $\pi$, etc.

d) Finalmente, si las letras gráficas fueran consideradas por los diccionarios como representaciones abreviadas de sus correspondientes nombres, tampoco se explica por qué la mayoría de ellos definen las entradas en cuestión como representantes no de los nombres, sino de las letras mismas en cuanto componentes de un sistema gráfico en un orden preestablecido o incluso de los fonemas asociados a ellas. A este último respecto, cabe resaltar por cierto que resulta más coherente el Diccionario del español actual (DEA) de M. Seco et alii (1999), donde las letras en su forma gráfica se hallan remitidas al registro léxico correspondiente, excepto, naturalmente, en el caso de las vocales, dada la coincidencia de su forma gráfica y léxica. Hay que observar además que en este diccionario las letras gráficas no se hallan categorizadas mediante marca alguna, aun cuando su remisión al sustantivo correspondiente parece indicarnos que los autores se inclinan a favor de su consideración también como sustantivos.

En resumidas cuentas la interpretación de las letras gráficas como abreviaturas de los nombres de las letras no parece ser, al menos de primera intención, el punto de vista adoptado por el DRAE ni otros muchos diccionarios, como -por poner tan solo un par de ejemplos más- el Diccionario general e ilustrado de la lengua española Vox (DGILE 1987) o el Diccionario Salamanca de la lengua española (DSLE 1996), precisamente porque para las letras léxicas utilizan definiciones en que la entrada se clasifica como nombre, esto es, se trata claramente de definiciones formuladas en lo que viene llamándose "metalengua de signo", frente al caso de los artículos encabezados por letras gráficas, cuyas definiciones las clasifican como letras y, por lo tanto, si realmente los definidos estuvieran tomados como abreviaturas de las letras léxicas, nos encontraríamos ahora ante definiciones en "metalengua de significado". Tal proceder, sin embargo, no parece lógico por lo poco económico del 
procedimiento: al interpretarse como la misma unidad léxica, lo obvio sería proceder como hace M. Seco et alii en su DEA (1999), esto es, remitir de un artículo a otro. Para mí no hay la menor duda de que, a propósito de las entradas en letras gráficas, lo que se pretende definir en estos diccionarios es precisamente la letra y no el nombre que le corresponde; se trata, pues, también en este caso de definiciones en "metalengua de signo": la definición forma parte de una construcción atributiva con un verbo implícito ser, no se trata de un complemento directo de un también verbo implícito significar. Notemos además que, si el lexicógrafo, al redactar el artículo correspondiente, estuviera realmente pensando en la palabra y no en la letra en cuestión, ¿qué sentido tendría añadir al final del artículo la coletilla Su nombre es..., tal como se registra, por ejemplo, en el siguiente artículo del DSLE (1996):

b. s. f. Segunda letra del alfabeto español que representa un sonido de articulación bilabial, oclusiva y sonora o un sonido de articulación bilabial, fricativa y sonora. Su nombre es "be".

Todo lo dicho nos lleva necesariamente a reconocer que las letras gráficas tal como aparecen estudiadas en los diccionarios resultan bastante confusas, pues, por una parte, parece que son efectivamente representación de sí mismas, esto es, se registran como grafemas o elementos distintivos mínimos de la escritura (así, por ejemplo, cuando se dice que ocupan un determinado orden en el sistema gráfico a que pertenecen); pero, por otro lado, parecen al mismo tiempo entenderse como equivalentes o sustitutos de sus respectivos nombres, pues de otro modo no se explica, como queda observado, la categorización de que son objeto en unos casos o la remisión en otros menos frecuentes al artículo encabezado por el nombre de la letra en cuestión, y, finalmente, se suelen encima identificar con el fonema o fonemas que representan, llegándose incluso a atribuir a la letra en cuestión una determinada característica fónica o pronunciación concreta. Como ejemplo de todo esto, permítaseme reproducir el siguiente artículo del Gran diccionario de la lengua española de SGEL (GDLE 1995):

B [bé] $s / f$ 1. Segunda letra del alfabeto. Es consonante bilabial sonora. En posición intervocálica es fricativa. En castellano la $b$ y la $v$ son homófonas [...] ORT En mayúscula, $B$. 
La confusión entre los niveles gráfico, léxico, fonético y fonológico es, como puede observarse, patente, y ello pese a ser este un diccionario en que se pone especial cuidado en la indicación del nivel fónico de la lengua, característica en la que por cierto pretendió en su día ser novedoso.

\section{LA LETRA COMO GRAFEMA}

Pero vamos a prescindir por unos momentos de la cuestión de si las letras gráficas deberían o no figurar como entradas en los diccionarios. Aun en el caso de que debieran figurar, desde luego lo que ante todo tendrían que preguntarse los lexicógrafos al enfrentarse con la redacción de los artículos correspondientes es qué convendría definir en este caso: ¿la letra como unidad gráfica distintiva, esto es, como grafema, o más bien la letra como signo o representante de un fonema e incluso, tal vez, según parecen pensar algunos, de un sonido del habla, o, en fin, la letra como signo abreviado de su propio nombre? Desde luego, lo que nunca debería hacerse es mezclar de forma caótica e indiscriminada todos esos aspectos tal como viene ocurriendo normalmente, cosa que en verdad nada o muy poco ayuda a quienes consultan el diccionario.

Desde luego si la letra se entiende como pura realización de un grafema o unidad distintiva mínima en el nivel gráfico, de acuerdo con la definición de algunos diccionarios, una posibilidad será definirla tal como se viene haciendo tradicionalmente, esto es, atendiendo al lugar que ocupa dentro del alfabeto o abecedario, habida cuenta de la ordenación fija a que están convencionalmente sometidas las letras dentro de éste. Ese orden se indica, como es habitual, en la definición por medio de un ordinal, según hace, por ejemplo, el DRAE:

d. f. Quinta letra del abecedario español, y cuarta de sus consonantes.

Una forma por cierto original de establecer ese orden es el seguido por el Diccionario para la enseñanza de la lengua española de la Universidad de Alcalá (1995) consistente en definir cada letra poniéndola en relación con la que le precede; así,

$\mathbf{M}, \mathbf{m} 1 \boldsymbol{f}$. Letra que en el alfabeto español sigue a la $l$. 
Digamos en todo caso que se trata de definiciones absolutamente externas que nada dicen acerca de la verdadera naturaleza del objeto definido y, además, guardan el peligro de servir para objetos diferentes, habida cuenta de que no siempre se clasifican como letras las mismas realidades gráficas; así, por ejemplo, hasta hace bien poco el dígrafo ch era considerado como una letra más -la cuarta- de nuestro alfabeto, lo que determina que el DRAE, según acabamos de ver, defina d como quinta letra, definición que hoy, en cambio, corresponderá a e. En fin, no niego que el procedimiento sea lícito, pero no hay duda de que resulta poco esclarecedor o explicativo.

Desde luego, de ser aceptadas como entradas del diccionario, la mejor forma sin duda de definir las letras gráficas sería atendiendo a su naturaleza grafemática, esto es, viéndolas como realizaciones de grafemas o unidades distintivas, paralelas -no necesariamente equivalentes-a los fonemas, en la medida en que, al igual que éstos, actúan en la escritura como unidades mínimas distintivas, según lo demuestran parejas como basta / vasta, hasta / asta, ca / ka, etc., solo por poner casos en que no se da correspondencia fonológica, esto es, sin una contrapartida o equivalencia en el nivel fónico ${ }^{11}$. Esto supuesto, definir una letra debería consistir en una enumeración de los rasgos gráficos pertinentes, esto es, aquellos por los que, por ejemplo, 1 es distinta de b, ésta de h, h de $n$, etc. Aunque, que yo sepa, tales rasgos non han sido todavía establecidos por nadie, excepción hecha del -a mi juicio, poco aceptable-intento protagonizado por E. Ruiz ${ }^{12}$, creo que serían fácilmente segmentables partiendo, por ejemplo, de parejas mínimas del tipo i $/ \mathrm{j}, \mathrm{n} / \tilde{\mathrm{n}}, \mathrm{n} / \mathrm{h}, \mathrm{c} / \mathrm{e}, \mathrm{l} / \mathrm{d}$, $1 / b$, etc. cuyas diferencias, como se ve, estriban en la presencia frente a la ausencia en cada una de ellas de un determinado rasgo gráfico (son,

11 Claro que lo más corriente es que esa contrapartida exista, de modo que con oposiciones gráficas como basta - pasta, cama - capa, manta - menta, etc. se corresponden, respectivamente, las oposiciones fonológicas /básta/ - /pásta/, /káma/ - /kápa/, /máNta/ - /méNta/: hay, como se ve, una relación biunívoca entre las distinciones establecidas por letras y las establecidas por fonemas. Pero, evidentemente, esto no es siempre así.

12 Cfr. E. Ruiz (1992: 113 y ss.). 
pues, verdaderas oposiciones privativas): $\mathrm{j}$ implica frente a $\mathrm{i}$ una prolongación por debajo de la caja del renglón, ñ no es más que una n con tilde, h presenta una prolongación hacia arriba del trazo inicial en relación con n, etc. El caso es que, una vez aislados los rasgos gráficos pertinentes, éstos podrían ser sometidos a una verbalización mediante una terminología inventada $a d h o c$, lo que haría posible establecer un sistema de definiciones relativas al conjunto de todas las letras.

Aunque no es mi intención llevar a cabo aquí esa tarea, se me ocurre -solo a modo de hipótesis- que una primera caracterización de las letras gráficas podría venir dada por el hecho de presentar o no cuerpo, entendiendo por éste la parte inscrita, dentro de la caja del renglón, en una figura geométrica (círculo o rectángulo), esto es, con trazos en dos dimensiones, vertical y horizontal. Así, serían letras con cuerpo a, o, b, $\mathrm{n}$, q, etc., frente a l, i, j, que, por consistir en un puro trazo vertical, carecerían de dicho cuerpo. Otra distinción podría venir dada por el hecho de que las letras presenten un trazo por encima o por debajo de la caja del renglón, como es el caso de p, q, b, h, frente a o, m, n, r, i, etc. A su vez las letras con cuerpo podrían subdividirse según que éste sea totalmente cerrado, como en el caso de o, o, por el contrario, con una abertura por arriba (así u) o por abajo (n) o por la derecha (c). En definitiva, podríamos proponer definiciones como las siguientes:

o. Letra con cuerpo cerrado.

b. Letra con cuerpo cerrado y trazo alto a la izquierda.

d. Letra con cuerpo cerrado y trazo alto a la derecha.

h. Letra con cuerpo abierto por abajo y trazo alto a la izquierda.

p. Letra con cuerpo cerrado y trazo bajo a la izquierda.

l. Letra sin cuerpo con trazo alto.

m. Letra de doble cuerpo abierto por abajo.

w. Letra de doble cuerpo abierto por arriba.

No hace falta notar que el sistema gráfico así concebido constituye, como muy bien ha hecho notar L. Contreras ${ }^{13}$, un verdadero sistema de oposiciones, donde existen, como acabamos de ver, oposiciones priva-

13 Cfr. L. Contreras (1995: 123 y ss.). 
tivas (una letra aporta un rasgo del que carece la otra: $\tilde{n}-\mathrm{n}, \mathrm{o} h-1$ ), equipolentes como $\mathrm{h}-\mathrm{k}$, graduales como o $-\mathrm{O}, \mathrm{c}-\mathrm{C}, \mathrm{y}$, por otro lado, bilaterales (lo que tienen en común no se repite en ningún otro caso: c e), multilaterales (lo común se repite: $1-\mathrm{h}$, pues existe también b y d con el mismo trazo vertical), proporcionales (se repiten las diferencias: lo que separa a $\mathrm{p}$ de $\mathrm{q}$ es lo mismo que diferencia a b y d), etc. Se dan incluso verdaderos haces correlativos, como el siguiente:

$$
\begin{aligned}
& \mathrm{p}-\mathrm{q} \\
& \mathrm{l} \mid \\
& \mathrm{b}-\mathrm{d}
\end{aligned}
$$

donde, como se ve, $\mathrm{p}$ se diferencia de $\mathrm{q}$ en la misma medida que se diferencian b y d, así como, al mismo tiempo, $\mathrm{p}$ y b presentan las mismas diferencias que q y d. Se puede hablar incluso de neutralizaciones, como la que se da entre $n$ y $m$ cuando van inmediatamente seguidos por $b$ o p, o entre letras mayúsculas y minúsculas en inicial absoluto o después de punto $(.)^{14}$.

Hablando de mayúsculas y minúsculas, se plantea el problema de si han de considerarse variantes de los mismos grafemas (como variantes de las mismas letras se vienen entendiendo tradicionalmente y así, de hecho, son consideradas en algunos diccionarios, al figurar mayúscula y minúscula en la entrada o enunciado de los artículos correspondientes ${ }^{15}$ ) o como representantes de unidades grafemáticas

14 No comparto la afirmación de L. Contreras (1995: 138) según la cual se produciría neutralización entre e/y por el hecho de que la conjunción copulativa presente ambas formas, o entre c/z en la palabra cenit, también escrita zenit, etc. No hay neutralización sencillamanete porque ambas parejas carecen de una base de comparación exclusiva, lo que implica la inexistencia de un archigrafema; además en el primer caso la igualación no se produce en el nivel grafemático, sino en el morfológico, y en el segundo caso la igualación tampoco se produce en el nivel grafemático, aunque sí en el gráfico, pero entendidas las letras como signos o representantes de fonemas, es decir, como representantes de / $\theta /$. Lo mismo ocurre con b/v en bargueño, palabra que admite también la grafía con v, caso citado asimismo por L. Conteras. Ver más adelante.

15 Tal es el caso, por ejemplo, del Diccionario de Alcalá (1995). La práctica no es frecuente porque la mayúscula se emplea como rúbrica al inicio de las entradas que comienzan por esa letra, y la minúscula sola como entrada del artículo. 
distintas. Desde luego esto último parece evidente dadas oposiciones como Mm 'Miriámetro' / mm 'milímetro', rosa 'flor' / Rosa 'nombre de persona', este 'demostrativo' / Este 'punto cardinal', etc. Otro argumento que favorece esta interpretación vendría dado por el hecho de que, en muchas letras, mayúscula y minúscula no se diferencian exclusivamente por el tamaño, sino también por la forma (comp. A/a, B/b, $\mathrm{R} / \mathrm{r}, \mathrm{N} / \mathrm{n}, \mathrm{Q} / \mathrm{q}$, por ejemplo). La utilización, no obstante, de mayúsculas y minúsculas viene la mayor parte de las veces regulada por el puro contexto gráfico - por ejemplo, después de punto (.)-, cuando su empleo no es absolutamente libre. Ello significa que lo más frecuente es que mayúsculas y minúsculas actúen como verdaderos alógrafos o variantes y solo en contadas ocasiones se utilizan con función diacrítica o distintiva, lo que nos lleva a postular la existencia de lo que Coseriu llama una subdistintición ${ }^{16}$ : se trata de oposiciones ocasionales.

\section{LA LETRA COMO SIGNO O REPRESENTANTE DE UN FONEMA}

Después de esta, pienso que necesaria, digresión sobre la naturaleza grafemática o distintiva de las letras de nuestro alfabeto, aspecto prácticamente desatendido en la lexicografía, paso a ocuparme de las letras gráficas como signos, aspecto -este sí- en el que se suelen centrar las informaciones contenidas en los diccionarios al uso. Otra cosa es que éstas sean adecuadas, pues con frecuencia, cuando no son inexactas ${ }^{17}$, consisten, como señalé antes, en una mezcla de niveles, de lo fonético con lo fonológico ${ }^{18}$ y de éstos con lo gráfico, con tendencia, por otro la-

16 Cfr. E. Coseriu (1981: 248).

17 Así, por citar tan solo un ejemplo de los muchos que se podrían poner, en el ClaVE (1997) se dice de la b que "representa el sonido consonántico biblabial sonoro", sin caer en la cuenta de que esas mismas características corresponden también a m, y, por lo tanto, falta añadir el rasgo "oral".

18 Por ejemplo, es casi general definir los fonemas correspondientes a las letras no por sus rasgos propiamente distintivos, sino por los correspondientes a uno de sus alófonos, tomado como prototipo. Así cuando se dice - por ejemplo en el DuE (19661967) - que b "representa un fonema bilabial oclusivo sonoro" (habría que añadir "oral"), sin tener en cuenta que, fonológicamente, no es oclusivo, pues tiene una va- 
do, a un enciclopedismo injustificado. Me permito recordar a este respecto el artículo, anteriormente citado, del GDLE (1995) correspondiente $\mathrm{a} b$, donde ésta se define como letra, como consonante bilabial con una variante fricativa y, finalmente, se hace equivalente fonético de v; confusiones semejantes aparecen también, a propósito de la misma letra, en el DuE de $M^{\mathrm{a}}$ Moliner (1966-1967), como veremos más abajo. En fin, por las informaciones contenidas en los diccionarios sobre las letras se podría seguir por cierto la evolución experimentada por los estudios de fonética y fonología de nuestra lengua a lo largo de los años. Y así, por ejemplo, en comparación con los conocimientos que hoy poseemos sobre la materia nos resulta curioso, por ejemplo, leer en el Diccionario de autoridades (1726-1737) que f y 1 son semivocales, que b es una letra muda porque "su sonido es más sordo", o que h no es propiamente una letra porque "es solamente aspiración", etc.

Desde luego, en la interpretación más corriente que se viene haciendo de las letras, tanto en los diccionarios como fuera de ellos, éstas no tienen otro objeto que la representación de los sonidos del lenguaje. Y tal es, en efecto, la finalidad con que nacieron y podríamos decir que es su, en principio, verdadera razón de ser; pero solo en principio, porque, como es obvio, no hay una relación biunívoca entre sonidos del lenguaje y grafemas, aun cuando en el caso del español exista una bastante aproximada correspondencia, que lleva a algunos a sostener, sin duda exageradamente, que nuestra lengua dispone de una "escritura fonética”. Si ello fuera así, tendríamos en español idéntico número de grafemas que de fonemas, cosa evidentemente falsa: en nuestro alfabeto hay una letra, la hache - con valor grafemático indiscutible, dada su función distintiva, por ejemplo en hasta / asta-, que no representa ningún sonido; otras, en cambio, pueden, según los casos, transcribir fonemas diferentes (así c o g) o, por el contrario, representar el mismo fonema que

riante fricativa, y tampoco es necesariamente bilabial: basta con decir que es labial, pues dicho fonema no ha de realizarse necesariamente con ambos labios (de hecho una labiodental sonora sigue interpretándose como /b/ en español). Pero, naturalmente, no voy a abordar aquí una crítica pormenorizada de las definiciones concretas y ni siquiera de las doctrinas fonológicas en que se basan, cosa que podría ser tema de un estudio independiente. 
otra u otras (por ejemplo, b, v y w) y, finalmente, una letra como x corresponde a un grupo de sonidos distintos, así como ocurre lo contrario: un grupo de letras -por ejemplo ch- representan un sonido o fonema único (al menos así interpretado en la fonología del español).

Ahora bien, en la consideración de las letras como signos, lo primero que hemos de preguntarnos es a qué nivel fónico corresponde lo representado. Dicho de otra manera, como signos ¿qué representan realmente las letras? ¿Los fonemas, esto es, los sonidos lingüísticos en su nivel más abstracto o, por el contrario, las realizaciones concretas o puras variantes fonéticas de esos fonemas? Los diccionarios, como ya queda observado, no siempre son claros al respecto, oscilando entre una y otra consideración, cuando no confunden, de hecho, ambos aspectos o, lo que es todavía más grave, confunden asimismo lo representado con el representante, esto es, lo fónico con lo gráfico, atribuyéndole a éste características propias de aquél. Como ejemplo de confusión entre lo fonológico y fonético, obsérvese la información que, a propósito de $\mathrm{b}$, se ofrece en la edición abreviada del Due de $\mathrm{M}^{\mathrm{a}}$ Moliner (DuE(A) 2000):

\section{b f. Segunda letra del alfabeto. Representa un fonema bilabial oclusi- vo sonoro}

donde, por una parte, se afirma que dicha letra representa un fonema, pero luego lo que se define no es propiamente el fonema $/ \mathrm{b} /$, sino uno de sus alófonos: [b]. Pero el confusionismo es sin duda todavía mayor en la edición no abreviada en su última versión, donde se añade:

b 1 f. [...] Después de pausa o detrás de "m" o "n" es oclusiva y, en los demás casos, fricativa. En final de sílaba y seguida de "s" u otra consonante, se debilita hasta el punto de desaparecer en muchos casos: es raro oír pronunciar "obscuro" u "obstruir", siendo lo corriente "oscuro" y "ostruir".

Notemos que aquí se sigue hablando de la letra b, que es el sujeto de los dos enunciados que siguen, y de donde la concordancia en femenino (oclusiva, fricativa); pero se le están atribuyendo - ja una realidad gráfica!- características y comportamientos propios de una realidad fónica. Por otro lado, al decir que desaparece en obscuro y obstruir no es- 
tá claro si se refiere a la grafía (existen en efecto obscuro y oscuro) o tan solo al nivel fónico (ostruir no existe como forma gráfica y de hecho no se registra en el DUE).

El DRAE, modelo lexicográfico ampliamente imitado por una buena parte de diccionarios del español, parece inclinarse por la interpretación de las letras como representantes de sonidos, esto es, de unidades fonéticas y como tales las caracteriza o describe en los artículos correspondientes. Así, por ejemplo,

f. [...] Representa un sonido con articulación labiodental fricativa sorda.

i. [...] Representa el sonido que se pronuncia elevando hacia la parte anterior del paladar el predorso de la lengua algo más que para articular la $e$, y estirando también los labios algo más hacia los lados.

La distinción, por lo demás, entre el plano fónico y el gráfico aparece en general bastante clara, al utilizar casi en todos los casos el verbo representar como enlace entre la letra-entrada y la realidad fónica indicada. Pese al cuidado observado en este punto por la Academia, no deja, sin embargo, de producirse algún que otro desliz, como ocurre, por ejemplo, cuando en el artículo sobre la u dice:

Pronúnciase [la u, no el sonido que ésta representa] emitiendo la voz con los labios algo más alargados y fruncidos que para pronunciar la $o$ y con la lengua más retraída y más elevada en su dorso hacia el velo del paladar.

O cuando hablando de $\mathrm{v}$, observa que

Su articulación [de v], por lo tanto es bilabial y sonora, oclusiva en posición inicial absoluta o después de nasal [...]

Verdaderamente la confusión de lo gráfico con lo fónico, detectada incluso a veces en la literatura lingüística especializada ${ }^{19}$, no parece obedecer a otra cosa que a la tendencia generalizada de los hablantes a identificar el signo con la cosa representada. Es en realidad esa tenden-

19 F. Dubert García (2000) ha llamado recientemente la atención sobre este hecho, aunque circunscribiéndose al campo de la fonología gallega. 
cia la que nos lleva, por ejemplo, a calificar de feas o malsonantes ciertas palabras solo por el hecho de referirse a objetos o realidades desagradables o socialmente mal consideradas. Pero ello, lógicamente, no justifica que esa práctica - presente en el lenguaje corriente- sea lícita en estudios de carácter científico como se supone que debe ser un diccionario, el cual, lógicamente, debe buscar la máxima propiedad y precisión en el uso de la lengua. En el caso que nos ocupa es claro que una cosa son las letras, realidades de tipo gráfico, y otra muy distinta los sonidos, de naturaleza articulatoria o acústica, que esas letras representan: de las primeras podemos decir que se escriben, que se leen, que son mayúsculas o minúsculas, redondas o cursivas, etc.; pero no que son palatales, fricativas o sonoras, que se pronuncian o articulan, o que suenan de esta manera o de la otra, porque estas características corresponden en exclusiva a realidades sonoras, no gráficas. Adelantemos, no obstante, que este hecho evidente no tiene, por otro lado, nada que ver con la posibilidad ofrecida por la lengua de emplear en la práctica expresiones del tipo hache muda, o abierta, ene velar o incluso letras mal pronunciadas, sencillamente porque, como veremos más adelante, estas expresiones vienen dadas por un nivel de representación diferente al que ahora nos estamos refiriendo.

Pero volviendo a la pregunta que nos plateábamos antes de si lo que representan las letras son los fonemas o las realizaciones fonéticas de éstos, parece lógico aceptar que, excepción hecha de h, en el caso del español representan normalmente fonemas y, por lo tanto, en los correspondientes artículos deberían conectarse exclusivamente con el fonema o fonemas representados. Es lo que hace, aunque indirectamente (en las definiciones de las letras léxicas), M. Seco et alii en su DEA (1999), cuando dice, por ejemplo, de efe que es

Letra del alfabeto $(F, f)$, que en español corresponde al fonema /f/

definición adecuada, pero insuficiente porque presenta una pista perdida, dado que en ninguna parte del diccionario se define tal fonema. Una forma de definir correcta sería, por tanto, esta otra:

f. Letra que representa el fonema consonántico oral labial fricativo sordo /f/. 
Naturalmente, en los casos en que la letra pudiese representar unidades fonológicas distintas, habría que contar con acepciones también diferentes; por ejemplo,

c. 1. Letra que, cuando le sigue e, i, representa el fonema oral dental fricativo plano $/ \theta /$ en el español estándar peninsular, o el fonema oral dental fricativo acanalado/s/ en el español americano. II 2. Letra que, cuando le sigue a,o,u, representa el fonema oral velar oclusivo sordo $/ \mathrm{k} /$. II 3. Letra que en posición final o ante una consonante representa el archifonema oral velar oclusivo /G/.

Y puesto que estamos hablando de signos, puede ocurrir que dos o más letras tengan idéntico representado, circunstancia en que ambas se distribuyen complementariamente de acuerdo con la normativa ortográfica, que solo en raras ocasiones permite la alternancia libre. Es, por ejemplo, el caso de b, v y w en español, que representan el mismo fonema /b/, produciéndose así entre ellas una especie de "sinonimia", aunque tan solo de tipo parcial, pues prácticamente solo en el caso de bargueño - vargueño es posible la alternancia de ambas letras.

No veo, por otro lado, razón para -contra lo que hace M. Seco et alii 1999- no aceptar como entradas, junto a las letras, los dígrafos ch y rr (1l, en cambio sí), puesto que éstos, como aquéllas, representan otros tantos fonemas del español. El Due de $\mathrm{M}^{\mathrm{a}}$ Moliner (1966-1967) presenta una incoherencia parecida al no registrar rr y sí, en cambio ch y ll, quizás porque solo éstos le ofrecen dudas en cuanto a su consideración como letras únicas o compuestas.

\section{LOS NOMBRES DE LAS LETRAS}

En realidad de verdad, como dejé sentado al principio, en el diccionario no debería figurar ninguno de estos signos gráficos, ni las letras ni los dígrafos, sencillamente porque, repito, no son unidades léxicas y, de serlo, no vendrían a constituir más que una especie de abreviaturas o siglas de los nombres de las letras que, ellos sí, por su naturaleza léxica, deben formar parte de la nomenclatura del diccionario. Pues bien, a las letras léxicas es a las que me voy a referir ahora en la última parte de este artículo. 
Los nombres de las letras y dígrafos, como $a$, be, ce, che, uve, equis, etc., como unidades léxicas ya he dicho que forman parte de un sistema o paradigma léxico bastante sencillo, cuyo archilexema es precisamente la palabra letra, la cual es definida, por ejemplo por el DRAE, entre otros diccionarios, con los dos sentidos siguientes:

Letra [...] f. Cada uno de los signos gráficos con que se representan los sonidos de un idioma. // 2. Llámanse también así a cada uno de estos sonidos.

Es decir, el sustantivo letra, por una parte, designaría un tipo de signo gráfico y, por otra, lo que ese signo representa, equivaliendo, por tanto a sonido lingüístico. En este mismo sentido se pronuncian prácticamente todos los diccionarios, incluido el más reciente de M. Seco et alii, que también define:

Letra I $f \mathbf{1}$ Signo gráfico de los que se usan para representar los fonemas del idioma $[\ldots]$ 2. Sonido o fonema.

Sólo el GDLE (1995) junto con el Diccionario de Alcalá (1995), más preocupados por destacar el aspecto fónico -en consonancia, por tanto, con los postulados de la lingüística moderna al respecto-, reducen el significado de la palabra letra al campo de lo estrictamente gráfico, lo que por cierto podría llevarnos a la conclusión de que estos diccionarios representan un evidente avance sobre los otros, que más parecen seguir anclados en los viejos supuestos tradicionales según los cuales, como es sabido, no existiría diferencia entre letras y sonidos. Pero, como ya se dejó entrever anteriormente, nada más lejos de la realidad, habida cuenta de que la misión del lexicógrafo en casos con este no debe consistir en reflejar el estado de conocimientos científicos sobre la materia, sino el uso real que los hablantes hacen del léxico correspondiente. Y en el caso concreto de la palabra letra, más que nos pese a los estudiosos de la fonética y fonología, no cabe duda de que son muchos - por no decir la mayoría- los hablantes del español que usan indistintamente letra para referirse tanto a los signos de la escritura como a los propios sonidos que éstas suelen representar. Quiero decir con esto que la distinción sonido - letra no es una distinción léxica del español -al menos del español común o estándar-, sino de la realidad constituida por el nivel de la 
expresión del lenguaje y que, por lo tanto, interesará a la ciencia lingüística, en la cual -eso sí- convendrá reflejarla terminológicamente, utilizando, por ejemplo, esas mismas palabras. En este orden de cosas, en español cabe hablar de la existencia de la palabra letra, con esa doble significación, al lado del término letra, perteneciente como tal a la terminología lingüística, que por su parte tan solo se entenderá como indicador de una realidad gráfica. Pues bien, el lexicógrafo, como lingüista que es, deberá lógicamente utilizar la palabra letra por supuesto en su sentido terminológico dentro de sus propias explicaciones, pero, al registrarla como entrada del diccionario, deberá referirse de hecho a ella como palabra del vocabulario general y, por lo tanto, se verá obligado a registrar los sentidos que de hecho posee en el sistema lingüístico ${ }^{20}$.

En otro orden de cosas sería interesante discutir acerca de la concepción que los diccionarios ofrecen de letra, objeto desde luego nada fácil de definir. Todos coinciden en considerarla como un "signo" que, a su vez, tendría la misión de representar un fonema o sonido (o grupo de ellos), en lo que se diferenciaría de otros "signos gráficos", como los de puntuación y, desde otra perspectiva, de los ideogramas o pictogramas, que representarían ideas o significados directamente. La principal dificultad que esta concepción supone es que, como es sabido, las letras no siempre representan fonemas o sonidos, como es el evidente caso de $h$ en español normativo ${ }^{21}, \mathrm{o}$, aun representándolos, no siempre se reflejan

20 Esto no obstante, ya dejé entrever más atrás que la utilización de letra con el sentido de sonido lingüístico es tan propio de nuestra lengua que los mismos que se preocupan por reducirla a su exclusivo contenido terminológico de pura representación gráfica del sonido y, por tanto, como algo opuesto a él, con relativa frecuencia caen, sin querer, en la incoherencia de usar esa palabra en su sentido tradicional abarcador del aspecto fónico, como ocurre, por ejemplo, en el siguiente enunciado correspondiente a la definición que la Academia registra en su Diccionario a propósito de balbucir:

Hablar o leer con pronunciación dificultosa, tarda y vacilante, trastocando a veces las letras o las sílabas. [El subrayado es mío]

$\mathrm{Y}$ de hecho expresiones existentes en la lengua, y, por tanto, muchas veces utilizadas incluso en la literatura lingüística, tales como letra muda, letra vocal o letra consonante, etc. no son más que un evidente reflejo de esa concepción.

21 Aunque existen excepciones; por ejemplo Sáhara, hall, holding se pronuncian generalmente [sáhara], [hól], [hóldin], con aspiración. 
fónicamente en todos los contextos, como es, por ejemplo, el caso de la b de substancia, de la p de psicológico en el español estándar, o de -s final de palabra en la pronunciación andaluza y de la d de la terminación -ado en el español vulgar, etc. La falta de correspondencia, en fin, entre letras y fonemas o sonidos es proverbial en otras lenguas como el francés y sobre todo el inglés, lenguas en las que, por lo tanto, no tendría sentido adoptar semejante tipo de definición. Más atrás ya me he referido a la necesidad de una consideración inmanente de las letras, esto es, desde su propio paradigma o sistema, y en este sentido quizás sería preferible sustituir su concepción como signos por la de unidades puramente distintivas independientes de los fonemas; esto es, como realizaciones de grafemas. Pero aun así surgen dificultades porque existen otros elementos gráficos, como los signos de puntuación, que también tienen esa misma función distintiva. Cabe entonces otra solución: considerarlas como miembros o componentes de un conjunto que denominamos alfabeto, solución que tampoco resulta viable dado que fácilmente nos encontraríamos ante un círculo vicioso al definir letra como 'cada uno de los componentes de un alfabeto' y, a su vez, alfabeto como 'el conjunto de las letras empleadas en un sistema de escritura'. Tal vez el problema podría solucionarse limitando el carácter distintivo de las letras al ámbito de la palabra gráfica, entendida ésta como una cadena de grafemas delimitada por dos espacios consecutivos en blanco. Así tendríamos:

Letra. Cada uno de los grafemas que entran en la composición de una palabra.

Debo observar, no obstante, que no forma parte de mis objetivos establecer aquí una definición de la palabra letra, sino más bien entrar en la cuestión del tratamiento que los diccionarios del español dan $-\mathrm{y}$, por otro lado, deberían dar- a las entradas constituidas por los hipónimos de letra, representados por lo que hemos llamado letras léxicas, esto es, por palabras como $a$, be, hache, equis, zeta, etc., correspondientes a los nombres de los componentes de nuestro alfabeto, junto con alfa, beta, gamma, épsilon, pi, etc. del alfabeto griego, o, en general, los nombres de las letras de cualquier tipo de alfabeto. 
Antes, sin embargo, de entrar de lleno en esa cuestión, me parece necesario observar que los nombres de las letras de nuestro alfabeto, que en realidad, lo mismo que los de otros sistemas alfabéticos, no constituyen otra cosa que una nomenclatura, presentan $-\mathrm{y}$ ello al margen de que su archilexema letra pueda referirse léxicamente tanto a realidades gráficas como fónicas- una clara polisemia en la lengua, dado que de hecho no solo sirven para denominar las letras gráficas sino también los fonemas e incluso los alófonos o sonidos del habla que los realizan. Quiero decir que palabras como ge, efe, ele, te o ese pueden tener como referentes no solo las letras del alfabeto, sino también los fonemas o sonidos con los que esas letras suelen corresponderse, lo que determina que al lado de expresiones como la letra eme o la letra te sea posible hablar -incluso en la literatura lingüística- del fonema a, fonema pe así como del sonido o alófono be oclusiva, del sonido jota , etc. cuando necesitamos verbalizar representaciones como /a/, /p/, [b] y [x], respectivamente. Nos encontramos, pues, ante un caso en que una nomenclatura tradicional, nacida para ser aplicada a las letras, es aprovechada a su vez por la fonética y fonología para referirse a las unidades fónicas, de manera que tenemos en realidad a estos términos funcionando en tres paradigmas léxicos diferentes: en el paradigma "letra", en el paradigma "fonema" y en el paradigma "alófono", es decir, en los tres niveles correspondientes a la expresión lingüística. Evidentemente, esta nomenclatura resulta insuficiente para denominar todas las posibilidades fonemáticas y sobre todo alofónicas de la lengua, lo que hace necesarias expresiones como o cerrada, ese ápico-alveolar, efe bilabial, por cuanto que para esas unidades no existen $-\mathrm{o}$ al menos no han sido creados- nombres o términos específicos. Discrepo, por tanto, de la opinión de F. Dubert ${ }^{22}$, para quien la

22 Cfr. F. Dubert 2000: 472-473. Con esto no quiero negar que de hecho existe ya desde antiguo un trasvase terminológico entre los niveles gráfico y fónico que demuestra esa confusión o, quizá mejor dicho, indistinción; por ejemplo, como ya he observado, cuando se habla de letras mudas o se dividen las letras en vocales y consonantes o, en fin, cuando se dice que tal letra suena o se pronuncia de esta manera o de la otra. Pero aun así tales expresiones no son, según hemos visto, lingüísticamente incorrectas; lo serían tan solo en el uso terminológico de la palabra letra, esto es, en un tratado de fo- 
utilización de semejantes expresiones implicaría una confusión entre los niveles gráfico y fónico: si cuando decimos o abierta estuviéramos pensando en la letra, podríamos aceptar también en su lugar la expresión *letra o abierta, cosa imposible a menos que entendiéramos el sustantivo letra en su significado corriente, no terminológico, de 'fonema o sonido' de la lengua.

En los artículos lexicográficos correspondientes a lo que vengo llamando letras léxicas, esto es, a las palabras be, ce, efe, ele, etc., la generalidad de los diccionarios españoles se olvidan por completo del carácter polisémico de las mismas, limitándose a registrarlas como denominaciones exclusivas de las letras o, en todo caso, relativas asimismo a otras realidades ajenas por completo al plano lingüístico de la expresión $^{23}$. Solo el DEA constituye la excepción en este caso, al considerarlas -aunque como una pura variación significativa dentro de la acepción gráfica y en casos esporádicos- también como denominaciones de los fonemas; así, comp.

ene $f 1$ Letra del alfabeto $(n, N)$, que en español corresponde al fone$\mathrm{ma} / \mathrm{n} /[\ldots]$ A veces tb. se llama así el fonema representado por esta letra.

Sin entrar ahora en lo acertado o desacertado de estas definiciones, digamos que en general los diccionarios adoptan en este caso dos tipos de definición diferentes:

nética, por ejemplo. Notemos, por otro lado, que dicho trasvase no siempre implica confusión de los dos niveles; así, por ejemplo, ya en la doctrina tradicional la palabra acento no significa lo mismo referida al nivel fónico (acento prosódico) que al gráfico (acentro gráfico o tilde), y hoy -sobre todo después de las últimas normas ortográficas de la Academia- se hace necesario distinguir entre diptongo (fónico) y diptongo (gráfico), considerándose este último constituido por toda agrupación de una vocal con i, u inacentuadas, o de éstas entre sí con acento en la segunda, independientemente de que coincidan o no con un diptongo fónico en la pronunciación; tal es la razón de que hoy no sea necesario acentuar, gráficamente, palabras como guion o huisteis, por ejemplo.

23 Así, por ejemplo, cuando de eme en segunda acepción se dice (cfr. DuE 1966-1967, s.v.) que se utiliza en numerosas expresiones como eufemismo por "mierda". 
a) La expresada en lo que viene llamándose "metalengua de signo" o "segunda metalengua", que es la empleada, por ejemplo, por el DRAE:

ge. f. Nombre de la letra g.

Donde, como se ve, no se indica el equivalente semántico, o lo que es lo mismo, el significado de la palabra ge, sino que, simplemente, se alude a su condición de signo lingüístico, al clasificarlo como nombre, esto es, como un tipo de realidad lingüística. Cabe destacar una nota curiosa: en la definición se incluye el objeto mismo que actúa como referente, esto es, la letra gráfica g.

b) En otros casos, sin embargo, se da una definición formulada en lo que se llama "metalengua de contenido", puesto que lo que se define es directamente el significado o quizás más exactamente el referente. Tal es lo que hace, por ejemplo, $\mathrm{M}^{\mathrm{a}}$ Moliner en su DuE (1966-1967):

ge f. Letra "g".

donde, como se ve, aparece también el referente, definido a su vez en otro lugar, el correspondiente a g. Mayor complejidad presenta a este respecto el DEA (1999), precisamente porque bajo la entrada del referente se limita a hacer una remisión a la letra léxica correspondiente, de modo que es en este caso donde se concentran todas las informaciones. El DEA utiliza en realidad ambos procedimientos de definición: la metalengua de contenido para la consideración como letra, y la metalengua de signo para su definición como fonema; así,

ge. $f$. Letra del alfabeto $(\mathrm{g}, \mathrm{G})$, que en español corresponde al fonema $/ \mathrm{x} /$ cuando está escrita ante $e$ o $i$, y al fonema /g/ en los demás casos [...] A veces se llama así cualquiera de los dos fonemas representados por esta letra.

La adopción en el segundo caso de la metalengua de signo se debe sin duda a que se trata de una explicación no concebida por sus autores como una definición propiamente dicha, sino como una mera aclaración marginal. Por lo demás, cabe notar que en el 
primer caso nos hallamos más bien ante dos definiciones encadenadas: una, la principal, en que ge es definida como letra del alfabeto, especificada de un modo directo por medio del correspondiente referente entre paréntesis, junto a otra, representada por la oración de relativo, en la que a su vez se define ese referente y, por lo tanto, si bien de un modo indirecto, se vuelve a definir la entrada. Se trata en definitiva de una definición en cierto modo pleonástica, pues bastaría en realidad con la primera parte, que es lo que se hace por cierto en el DuE (1966-1967).

El tipo de definición más frecuentemente adoptado por los diccionarios a propósito de las letras léxicas es el realizado en segunda metalengua, sin duda por ser el seguido por la Academia en todos sus diccionarios, especialmente en el DRAE, que, como es sabido, se toma generalmente como modelo. El procedimiento, por lo demás, está justificado probablemente por la necesidad de distinguir las letras léxicas de las letras gráficas, definidas previamente por el mismo diccionario en "primera metalengua", que es sin duda el procedimiento de definición preferible lexicográficamente hablando. $\mathrm{Y}$ a favor de esto, por otro lado, nos habla con toda probabilidad el hecho de que los nombres correspondientes a otros sistemas alfabéticos, como alfa, beta, gamma, delta, etc. sean, por el contrario, definidos preferentemente en "primera metalengua" ${ }^{24}$, debido seguramente a que en este caso las correspondientes letras carecen de entrada en su forma gráfica dentro del diccionario. Así, obsérvense, por ejemplo, las siguientes definiciones tomadas del DRAE:

alfa [...] f. Primera letra del alfabeto griego, que corresponde a la que en el nuestro se llama $a$.

gamma $[. .$.$] f. Tercera letra del alfabeto griego.$

24 Y digo preferentemente porque se detectan algunos casos en que la definición está expresada también en "segunda metalengua":

épsilon [...] f. Nombre de la $e$ breve del alfabeto griego.

Es decir, la Academia muestra de todas formas una cierta vacilación en la adopción del criterio. 
delta $[. .$.$] f. Cuarta letra del alfabeto griego, que corresponde a nues-$ tra $d$.

Desde luego lo que no debería faltar nunca en los artículos correspondientes a los nombres de las letras de nuestro alfabeto es, junto a su definición como unidades del sistema gráfico, su registro como representantes de unidades fónicas sean de orden fonológico o más concretamente fonético. Lexicográficamente hablando, no cabe duda de que nos encontramos ante acepciones o significados distintos - no de meras variantes, como parece reconocer Seco et alii en el DEA (1999)-, habida cuenta de que, repito, los nombres en cuestión forman parte en uno u otro caso de paradigmas léxicos distintos. Y ello por varias razones: en primer lugar porque, como ya hemos visto, poseen archilexemas diferentes y, además, porque, aunque en contados casos, algunas de esas denominaciones pertenecen en exclusiva a uno de esos paradigmas, los cuales, por tanto, no son absolutamente coincidentes. Así, por ejemplo, los sustantivos equis, $\mathrm{cu}$, uve doble o ce hache no se utilizan nunca para indicar sonidos ni fonemas, $\mathrm{y}$, por el contrario, gue o erre simple y erre múltiple no se usan normalmente con referencia a ninguna letra, así como, por otra parte, mientras che o elle son nombres de fonemas, hoy no se considerarían dentro de la nomenclatura de las letras, a no ser que en ella se incluyan los nombres de los dígrafos correspondientes. Por otra parte, un símbolo fonético como [w] jamás se verbaliza como *sonido uve doble, sino como semiconsonante $u$, así como tampoco la representación fonemática /x/ se verbaliza como *fonema equis, que no existe, sino como fonema jota (desde luego, sin duda porque ortográficamente se corresponde a veces con $j$ ), pero a su vez la letra así llamada en la representación fonética [j] no se lee, naturalmente, como jota, sino como semiconsonante $i$. Los diccionarios, en fin, confunden en general estos dos paradigmas, como ocurre, por ejemplo, con el caso de ere, que el DRAE define de la siguiente manera:

ere. f. Nombre de la letra $r$ en su sonido suave ${ }^{25}$

25 Esta palabra, y su correspondiente definición, aparece registrada por primera vez en la edición de 1884. 
frente a erre, que, según el mismo, correspondería a idéntica letra como representante del sonido fuerte, lo cual significaría que la denominación de la letra estaría condicionada al fonema o sonido que representa, cuando realmente no es así: el nombre de la letra habrá de ser siempre el mismo, independientemente de lo que represente -notemos que, paralelamente, tan ce es la que aparece en ceder como en casa o acto- $\mathrm{y}$, por lo tanto, habrá de llamarse erre tanto la que aparece en raza como en cara. La distinción erre - ere corresponde exclusivamente al léxico fonético: la primera palabra se refiere al sonido o fonema múltiple, que, gráficamente, corresponde a la letra $\mathrm{r}$-en inicial de palabra o después de $1, \mathrm{n}, \mathrm{s}-$ junto con el dígrafo rr, llamado erre doble, y la segunda es nombre exclusivo del sonido o fonema vibrante simple, que en la escritura se representa con la misma letra $r$ en las demás posiciones ${ }^{26}$. En resumen, solo erre es término de las dos nomenclaturas, no ere.

En cuanto al tipo de definiciones que deben adoptarse, hay que abogar, naturalmente, por las expresadas en "primera metalengua": en el nivel gráfico debería realizarse, según ya hemos visto anteriormente, una especie de descripción mediante los rasgos o trazos que definen esa letra como grafema, aunque cabe, como es habitual, definirla por el orden que, como tal letra, ocupa en el alfabeto, y, por otro lado, tampoco estaría mal utilizar, sola o acompañando a cualquiera de esas definiciones, la letra gráfica que se toma como referente, en una especie de definición mostrativa o indicativa, y, en segundo lugar, por lo que se refiere al nivel fónico, la definición tendrá que estar constituida por los rasgos fonológicos del fonema en cuestión, o por los rasgos fonéticos propios del alófono correspondiente. Como lo normal es que el nombre correspondiente se utilice por sí solo para designar un fonema, y solo cuando va acompañado de algún adjetivo indicador de un rasgo complementa-

26 Por eso acierta plenamente el GDLE (1995) al definir ere [ére] $s / f$ Nombre del sonido $r$ cuando es suave, aunque, incoherentemente, define por otro lado erre como "nombre de la letra $r$ cuando su sonido es fuerte" (copiando al DRAE). Más cauto el DEA (1999) considera a ere, que califica como raro, sinónimo de erre y, por consiguiente, ambos como nombres de la letra r. 
rio, puede designar un alófono, lo aconsejable es que las expresiones a que este tipo de denominación puede dar lugar se traten en el artículo como locuciones o lexías complejas. Así, por poner un ejemplo ideal, el artículo corresponde a be debería, a mi juicio, redactarse poco más o menos como sigue:

be. f. 1. Segunda letra de nuestro alfabeto constituida por un cuerpo cerrado y trazo alto a la izquierda (b). II 2. Lingutstica. Fonema consonántico oral labial momentáneo sonoro /b/. II oclusiva. La que aparece en inicial absoluta o después de nasal. $\| \sim \sim$ fricativa. La que se encuentra en cualquier otra posición.

Como curiosidad notemos, finalmente, que en la definición de la entrada como fonema los rasgos fonológicos de éste, por constituir un auténtico análisis del contenido de la entrada, se convierten aquí en verdaderos semas o rasgos semánticos distintivos.

\section{CONCLUSIÓN}

En conclusión, no tiene ningún sentido, desde mi punto de vista, seguir aceptando las letras gráficas, que son entidades totalmente ajenas al léxico de la lengua, como entradas en los diccionarios. Su presencia en éstos debería en tal caso limitarse a servir de cabecera o rúbrica de cada una de las partes o series de entradas en que, siguiendo el orden alfabético, tales obras se organizan; pero nunca deben ser objeto de artículos independientes, a no ser, claro está, que se entendieran como siglas o abreviaturas de las letras léxicas, esto es, interpretadas como denominaciones de sí mismas. Porque, evidentemente, los nombres de las letras constituyen un conjunto que sí, en cambio, forma parte con toda justicia del acervo léxico de la lengua. Constituyen en definitiva una nomenclatura o paradigma léxico cuyo hiperónimo o archilexema es precisamente el sustantivo letra, palabra que a su vez funciona, por una parte, dentro de la lengua común con la posibilidad de referirse tanto al plano gráfico como fónico y, por otra, en la terminología lingüística, como opuesto a fonema, esto es, con exclusiva referencia al plano estrictamente gráfico. Solo, pues, en el uso corriente de la lengua sería lícito decir, por ejemplo, que la letra be puede ser oclusiva o fricativa, 
expresión totalmente inaceptable desde el terreno de la lingüística, aun cuando no sería difícil encontrarla empleada en cualquier diccionario. Ahora bien, con este uso común, no terminológico, no hay que confundir expresiones, corrientes en cualquier estudio de fonética o de dialectología, como be oclusiva o ese coronal, por cuanto que en este caso no se habla propiamente de letras sino de fonemas, para cuya denominación la lingüística se apropió en parte de la nomenclatura tradicional utilizada para designar las letras del alfabeto: existe, en efecto, dentro de la terminología lingüística una nomenclatura parecida -no exactamente idéntica- a la de las letras, cuyo archilexema en este caso es, según nos movamos en el nivel fonológico o fonético, fonema y alófono o sonido, circunstancia que nos permite hablar del fonema pe, del archifonema ene o del alófono a palatal. Todo esto quiere decir que el artículo lexicográfico referido a las letras léxicas no deberá, en un diccionario monolingüe común, circunscribirse exclusivamente a definirlas como nombres exclusivos de las letras, sino también -siempre, naturalmente, que se registre esta parte de la terminología linguística- de los fonemas y de sus correspondientes realizaciones concretas; pero, eso sí, manteniendo una clara distinción de esos niveles, y no, como ocurre frecuentemente, realizando una mezcla inaceptable de los mismos.

\section{BIBLIOGRAFÍA}

Alvar EzQUeRra, M. (1993): Lexicografía descriptiva, Barcelona, Biblograf. (1980): "¿Qué es un diccionario? Al hilo de unas definiciones académicas", Lingüística Española Actual, II/1, pp. 103-119.

Clave (1997): Clave. Diccionario de uso del español actual, Madrid, Ediciones SM.

CONTRERAS, L. (1995): Ortografía y grafemática, Madrid, Visor.

Coseriu, E. (1981): Lecciones de lingüística general, Madrid, Gredos.

COVARRUBias, S. de (1611): Tesoro de la lengua castellana o española [manejamos la ed. de Madrid, Turner, 1977].

Dea (1999): Seco, M., O. de Andrés y G. Ramos, Diccionario del español actual, Madrid, Aguilar.

DeA(A) (2000): Seco, M., O. de Andrés y G. Ramos: Diccionario abreviado del español actual, Madrid, Aguilar. 
DGILE (1987): Diccionario general e ilustrado de la lengua española Vox, Barcelona, Biblograf.

Diccionario para la enseñanza de la lengua española, Barcelona, Biblograf-Univ. de Alcalá de Henares, 1995.

Drae (1992): Real ACAdemia Española (1992): Diccionario de la lengua española (DRAE), $21^{\mathrm{a}}$ ed., Madrid, Espasa.

Dsle (1996): Diccionario Salamanca de la lengua española, Madrid, Santillana-Univ. de Salamanca.

DuBERT GARCíA, F. (2000): "Sons e letras nas gramáticas clásicas do galego”, en J. L. Rodríguez, ed., Estudos dedicados a Ricardo Carvalho Calero, I, Santiago de Compostela, Univ. De Santiago/Parlamento de Galicia, pp. 463-476.

Due (1966-1967): María Moliner, Diccionario de uso del español, Madrid, Gredos; 2a . ed., 1998.

Due(A) (2000): María Moliner, Diccionario abreviado de uso del español, Madrid, Gredos.

GALENDE, J.C. (1997): Diccionario general de abreviaturas españolas, Madrid, Editorial Verbum.

GdLe (1995): Diccionario de uso. Gran diccionario de la lengua española, Madrid, SGEL, $1985 ; 7^{\mathrm{a}}$ ed.

González Calvo, J. M. (1998a): Estudios de morfología española, Cáceres, Univ. de Extremadura.

(1998b): Variaciones en torno a la gramática española, Cáceres, Univ. de Extremadura.

HaEnsCH, G. y otros (1982): La lexicografía. De la lingüística teórica a la lexicografía práctica, Madrid, Gredos.

Nebrija, E. A. (1495): Vocabulario de romance en latín, Salamanca [manejamos la edición de Madrid, Castalia, 1973].

Porto DapenA, J. Á. (1999): “Metalenguaje y metalexicografía”, Revista de Lexicografía, VI (1999-2000), pp. 127-151.

Real ACAdemia Española (1726-1737): Diccionario de autoridades, Madrid [manejamos la edición facs. de Madrid, Gredos, 1976].

_ (1927): Diccionario manual ilustrado de la lengua española, última ed., 1989, Madrid, Espasa.

— (1999): Ortografía de la lengua española, Madrid, Espasa.

RuIz, E. (1992): Hacia una semiología de la escritura, Madrid, Fundación Germán Sánchez Ruipérez.

WERnER, R. (1982): "La unidad léxica y el lema", en G. Haensch y otros (1982: 219-224). 